\title{
DETERMINATION OF ELASTIC CONSTANTS OF NATURAL MICA
}

\author{
Mohammed N. Alghamdi' ${ }^{1}$ Lidvin Kjerengtroen ${ }^{2}$, Jon Kellar ${ }^{3}$, and William Cross ${ }^{3}$ \\ 1 Department of Mechanical Engineering Technology, Yanbu Industrial College, P. O. Box 30436 \\ Yanbu Industrial City, Saudi Arabia, Email: mghamdi@yic.edu.sa \\ 2 Department of Mechanical Engineering, South Dakota School of Mines and Technology \\ 501 East Saint Josheph St. Rapid City SD, 57701 USA \\ Email: lidvin.kjerengtroen@sdsmt.edu \\ 3 Department of Materials and Metallurgical Engineering, South Dakota School of Mines and Technology \\ 501 East Saint Josheph St. Rapid City SD, 57701 USA \\ Email: jon.kellar@sdsmt.eduWilliam.Cross@sdsmt.edu
}

\begin{abstract}
The laminate structure of mica is very complex, mostly due to its anisotropic behavior in the direction of the property $\mathrm{C}_{33}$. Therefore, cutting mica sample is always challenging, particularly when relatively thick samples are desired. Thinner samples are relatively easy to cut and suffer little damage. However, in thick samples much damage can occur. This damage consists of cracks and boundary debonding between mica layers causing the properties to vary as a function of thickness. Therefore, the overall objective of this research is to determine the Young's modulus of natural muscovite mica using different thicknesses. Using tensile tester (Q $800 \mathrm{DMA})$, the Young's modulus of muscovite mica was found to be $178.3 \mathrm{GPa}$ for $20 \mu \mathrm{m}$ thick samples. This modulus agrees well with the literatures values for mica. The modulus decreased gradually when the sample thickness increased, reaching a mean value of $115 \mathrm{GPa}$ for $94 \mu \mathrm{m}$ thick samples. This indicates a decrease of about $35 \%$ Young's modulus when the thickness increased by $-79 \%$. Cutting muscovite with a specifically designed pressure fixture shows improvement in Young's modulus along the direction of the property $\mathrm{C}_{11}$, compared with the hand-cut fully exfoliated procedure. In addition, Young's modulus was not improved using pressure fixture cut compared with hand-cut samples. From these results it can be concluded that, the weak bonding which hold the layers together, could carry and/or transmit loads and is a key element to the overall stiffness of mica.
\end{abstract}

Keywords: Elastic properties; Laminate structure; Young's modulus; Composites.

\section{INTRODUCTION}

Mica is a generic name given to a complex group of more than 35 phyllosilicate minerals that have a layered structure and perfect basal cleavage. Delaminating these layers is relatively easy due to the weak bonding between the layers. Basically, each structural unit consists of one octahedral sheet (Os) sandwich between two tetrahedral sheets (Ts) as shown in Fig. 1 [1]. These sheets make one layer separated by non-hydrated interlayer cations (Is) [2].

When the layers are stacked together, it can be illustrated in the following sequence: (....I TOT I TOT I TOT I....). The cleavage plane (interlayer cations) of the muscovite consists of potassium layer $\left(K^{+}\right.$: Potassium 
carried positive charge) that holds the layers together. The distance between the two tetrahedral in one sheet as show in Fig. 1 (TOT: Octahedral sheet sandwiched between two tetrahedral sheets) including the oxygen bonds is $0.68 \mathrm{~nm}$ and the spacing distance of the cations (Is) (TIT: Interlayer cations sandwiched between two tetrahedral layers) is $0.32 \mathrm{~nm}[3]$.

Mica can be considered as a composite mineral because of its sequence structure which contains different properties at a nanoscale level. The interlayer cations are weakly bonded between the tetrahedral sheets (TIT), while covalent bonds exist are usually stronger between the TOT sheets. Both will result in anisotropic behavior in three dimensional (3D) planes. Therefore, any measured property is considered as a composite property, i.e. the Young's modulus measured in this paper is the composite modulus.

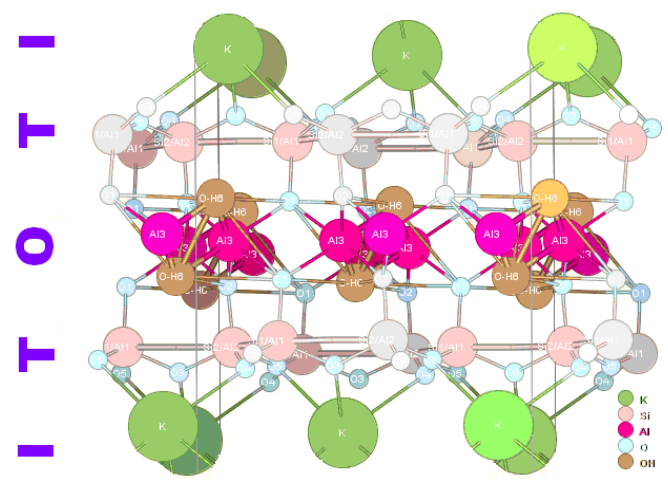

Fig.1. Schematic structure of mica: side view.

\section{ADVANTAGES \& APPLICATIONS}

Because of its high melting point $\left(-1320{ }^{\circ} \mathrm{C}\right.$ : muscovite) [1] and transparency, mica is often used in manufacturing oven windows,. On its own, mica can't hold charge because of its high dielectric strength. Mechanical properties have shown improvement when mica is used to reinforce thermoplastic such as nylon, polypropylene, polyester and polyethylene. In addition, muscovite can be used in improving dimensional stability of materials because of its low coefficient of thermal expansion [4]. This might take mica beyond the orbit for space explorations.

Mica is an anisotropic material in 3dimentions (3D) because it shows different properties in the direction perpendicular to the basal plane, which is shown in Fig. 2. However, mica is isotropic in 2-dimensions (2D): the directions which are parallel to the basal plane $[4,5]$.

Unlike fibers, mica would then reinforce composites equally in two directions. Also, mica is often used in applications where corrosion resistance is desired due to its inertness to water. Mica can also be used in ultra-light structural materials, because of its relatively low density $\left(2.7-3.2{\mathrm{~g} . \mathrm{cm}^{-3}}^{\text {: }}\right.$ muscovite) [4]. Antifriction properties, high aspect ratio, high modulus $(\sim 175 \mathrm{GPa})$ and strength contribute to making mica a unique mineral.

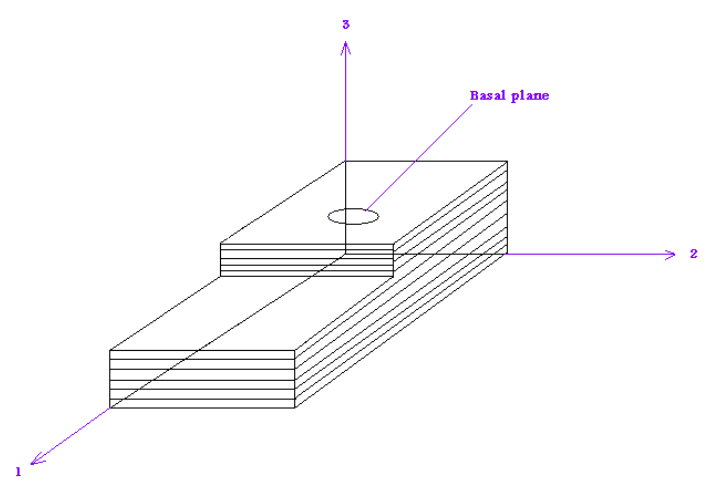

Fig.2. Coordinate system and the basal plane.

The objective of this research is to measure Young's modulus of muscovite mica laminates of different thicknesses.

\section{LITERATURE REVIEW}

In a stress-strain curve, usually a toe region $A B$ as shown in Fig. 3 is exhibited due to an artifact. During testing, the sample is placed between the grips and tightened. Due to tightening, the sample suffers in compression. By the time the experiment runs, it takes 
usually very small displacement until the sample is fully engaged and suffers the tensile load. The length $A B$ depends on the clamping techniques and the capability of the apparatus. This toe region which does not represent the properties of the material can be removed according to ASTM D882 [6], in order to obtain a correct Young's modulus

For materials that exhibit Hookean region, an extension to the line $C D$ to the zero stress can be constructed. Instead of point $A$, point $B$ is used to zero the strain. Now, the Young's modulus can be measured by taking any point in line $C D$ or its extension and divide it by the strain at the same point, counting $B$ is the zero strain point.

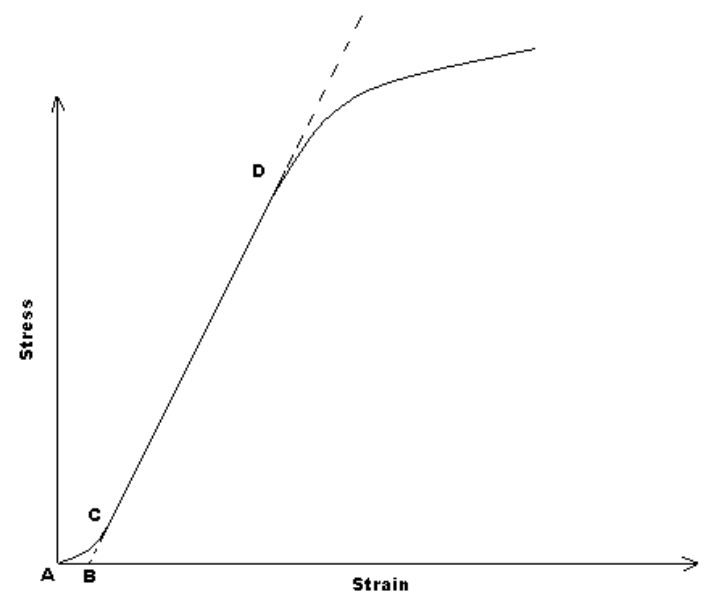

Fig.3. Stress-strain curve exhibit Hookean region.

Prasad [7] used an atomic force acoustic microscopy (AFAM) to measure the dynamic Young's modulus of some clay minerals. AFAM uses resonant frequency that is generated from a cantilever where the cantilever tip touches the sample to measure its stiffness. Dynamic Young's and shear moduli can be used to measure the Poisson's ratio according to ASTM E 1875 [8] if the material is homogenous, elastic and isotropic. Brillouin scattering is a method used to measure the reflection of the light from acoustic modes. McNeil [5] used Brillouin scattering to measure the thirteen independent elastic modulus of muscovite mica. The experiment measures the Brillouin shift $v$ and the relation between the effective elastic modulus $C_{\text {eff }}$ and the Brillouin shift given in Equation 1.

$C_{\text {eff }}=\rho v^{2}=\rho\left(\frac{v}{q}\right)^{2}$

Where $\rho$, is the density of the mica, $v$ is the sound velocity and $q$ is the phonon wavevector. Next, a relation is obtained between $C_{e f f}$ and the individual modulus $\left(C_{i j}\right)$ as a function of the propagation direction from Christoffel equation. As a result, McNeil found $E_{11}$ to be $176.5 \pm 1.1$ GPa using Brillouin scattering.

Katahara [9] used the mineral velocities to measure the elastic modulus. $V_{11}$ was found to be $8.03 \mathrm{~km} / \mathrm{s}$, and the modulus was calculated from the relation

$E_{i j}=\rho V_{i j}^{2}$

where $\rho$ is the density and $V_{\text {jy }}$ is the velocity in the mineral. According to Equation 2, $E_{11}$ $=179.9 \mathrm{GPa}$.

\section{EXPERIMENTS}

\section{SAMPLE PREPARATION}

In this section, different cutting procedures are presented. These procedures succeeded in minimizing the damage, but none of them were able to completely eliminate the damage occurring between the laminate structures of mica. Understanding how mica layers are bonded is important, because some properties might change as the delamination area changes.

Natural mica was purchased from SPI [10]. The original dimensions of the samples were $25 \times 25 \times 0.15 \mathrm{~mm}$; length, width, and 
thickness respectively. SPI uses a carbide die cutting tool to cut and prepare the mica samples [10]; however, the as-received samples still had some damage around the edges. This damage can be seen from the micrograph in Fig. 4 that indicates some cracks and possibly delamination.

In order not to leave fingerprints and hand oils on the samples, nitrile gloves were used when handling the samples. Fingerprints prevent visibility when viewing the samples under the microscope while hand oils might change the properties.

\section{CUTTING TEChNIQUeS}

Cutting mica is like cutting a strip of steel, and a good quality razor blade is recommended. For the best results, each cut requires a new blade, because no matter how good the blade is, the edge will be dulled [10].

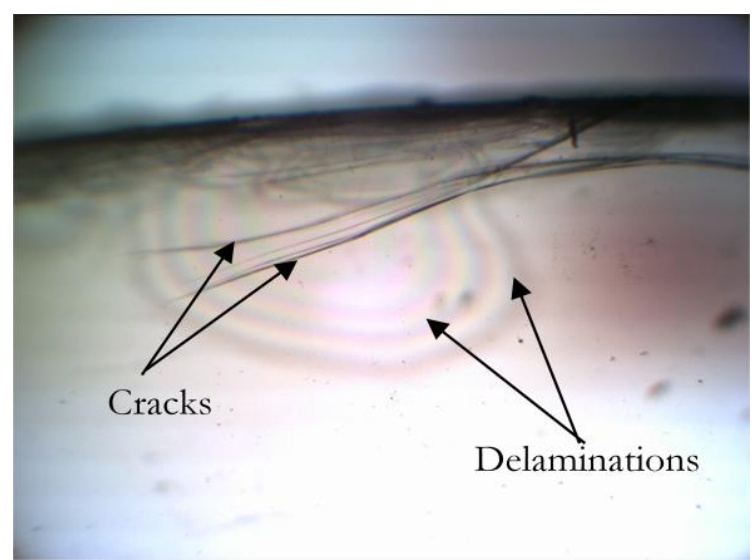

Fig.4. Sample as-received from the supplier.

Delamination of mica represents one of the stages of failure; therefore, cutting mica samples is challenging, particularly for thick samples and when minimum delamination is desired. Delaminations are usually located at the boundary, where the cut is made. Sharp scissors are another option to cut thin samples, but the problem is how to get a straight cut.

\section{Hand cut}

Cutting mica by hand requires a razor blade and steel ruler. The ruler is placed on top of the sample as shown in Fig. 5 and hand pressure applied before the blade passes through. Higher applied pressure minimizes the damage.

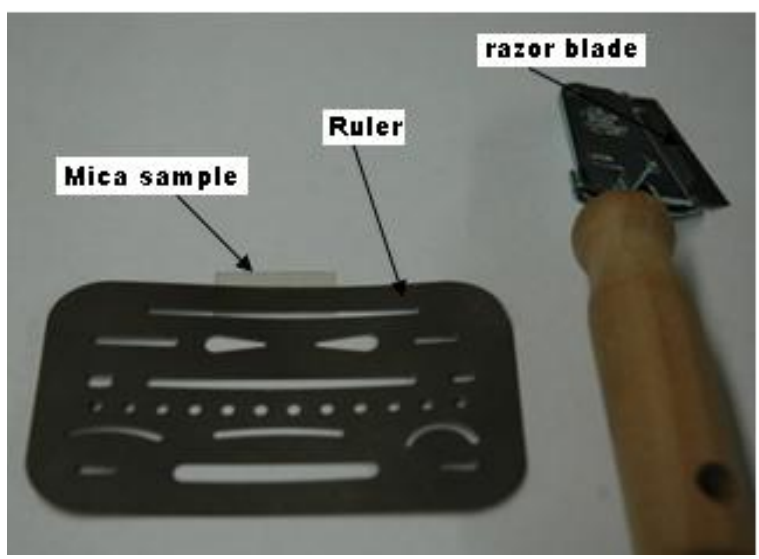

Fig.5. Hand cut using blade and a ruler.

The micrograph in Fig. 6 shows that the average length measured from the cutting axis to where delamination was reached is -707 $\mu \mathrm{m}$. This length varies, and depends on the force applied and the thickness of the sample. However, this length is always larger for thick samples when compared with thin samples.

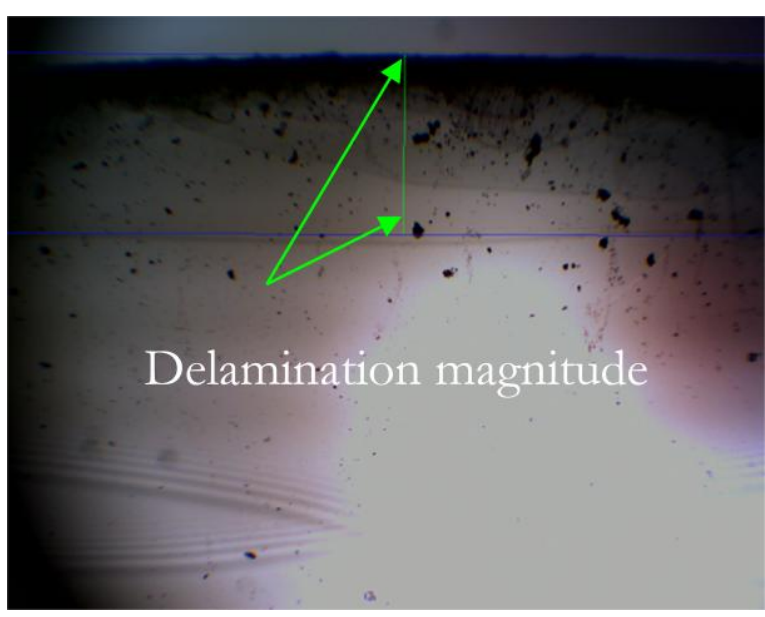

Fig.6. Hand cut, $80 \mu \mathrm{m}$ thick sample.

Cutting thin samples is different than cutting relatively thick samples; less damage occurs because of the fewer number of layers. This can be seen in the micrograph in Fig. 7. Even though it is relatively thin, it is difficult 
to determine how many layers have delaminated because of the large number, in this case $-35,000$ layers.

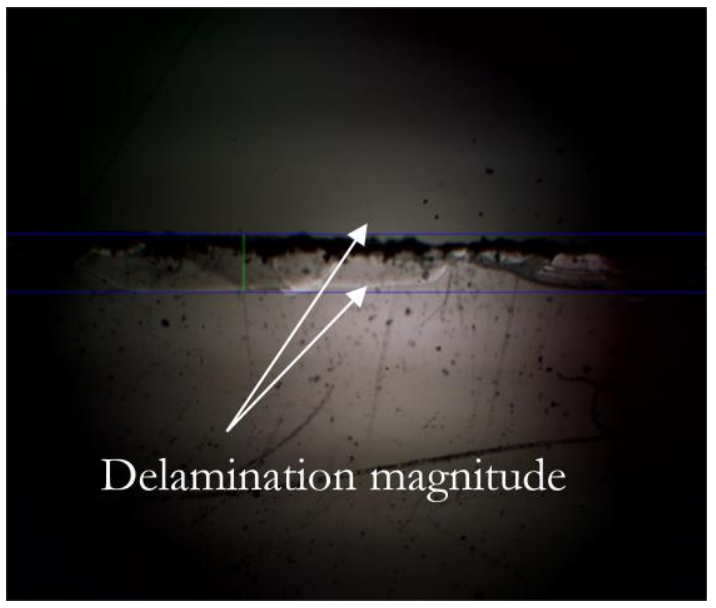

Fig.7. Hand cut, $35 \mu \mathrm{m}$ thick sample.

\section{Free side cut}

Another method used in cutting is shown in Fig. 8. Basically, the sample is placed between two steel plates and C-clamps are used to apply pressure on the sample in order to minimize the damage.

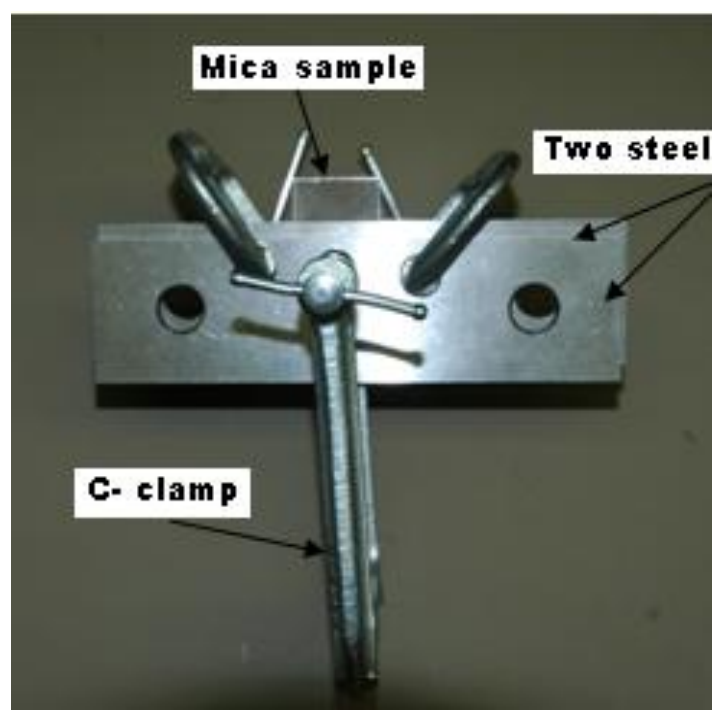

Fig.8. Sample placed between two strips of steel.

This technique had some disadvantages:

- Hard to adjust the sample dimension between the plates.

- Significant damage occurs on the free side of the sample.

\section{Fixture cut}

This technique used two machined aluminum plates, as shown in Fig. 9a) and b). The cover plate shown in Fig. 9b) has $-0.25 \mathrm{~mm}$ gap in the middle. This gap is designed to be used as a guide for the razor blade.
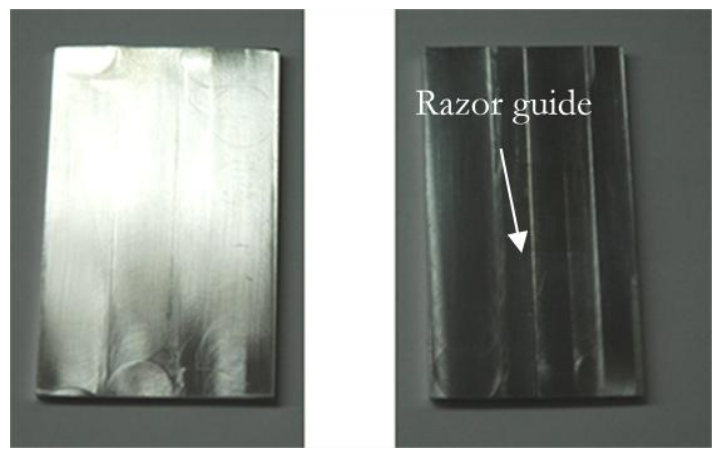

Fig.9. a) Fixture base plate; b) Razor runway plate.

The razor blade has approximately the same thickness as the designed gap; therefore, the blade will fit into the gap. As a result, the razor blade will be in touch with the sample (sandwiched between the plates). The samples are mounted between the fixture plates according to the following procedure:

- Initially, the sample is set on the razor runway plate.

- Next, the sample is adjusted and measured according to the gap axis.

- Slowly, the fixture base plate is placed in top of the razor runway plate.

- Gently, two C-clamps are set in a groove and tightened 1 turn.

Next, the razor blade will pass through the sample which has a constant applied pressure between the plates; Fig. 10 shows the assembly fixture in general. Usually, thin samples require a single pass of the razor blade, whereas multiple passes were needed to cut thick samples. When the cutting operation is finished, the C-clamps are loosened and the sample is ready to use. Samples were then taken by tweezers to the microscope, where 
they were finally investigated before being coded and placed in individual zipper bags.

Unlike the hand and free side cut, this technique guaranteed high pressure along all the surface of the sample, leading to less damage on the cut side and therefore deemed the best among the procedures examined.

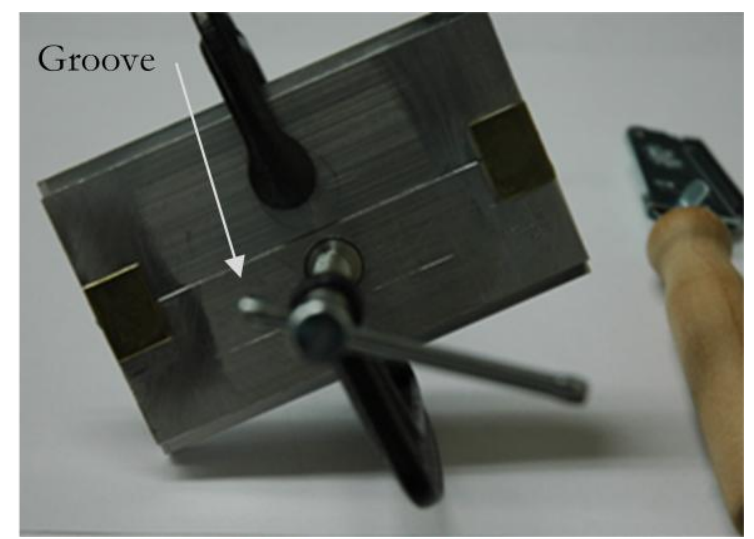

Fig.10. Fixture assembly.

It was proven under a microscope that this technique is the best when compared to the previous cutting procedures. Due to the high pressure applied on the sample, it did not delaminate much; in fact $-308 \mu \mathrm{m}$ is the average width of the damage as shown in Fig. 11.

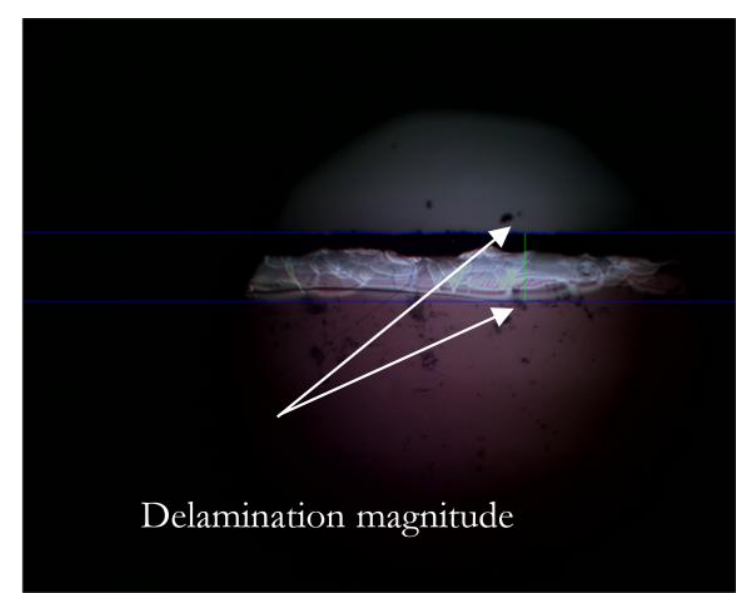

Fig.11. Delamination due to fixture cut, $78 \mu \mathrm{m}$ thick sample.

For the same sample dimensions of $15 \times 04 \mathrm{x}$ $0.078 \mathrm{~mm}$ (length, width, thickness), cutting by hand leaves more damage on the sample as shown in Fig. 12. The average delamination length in one side is $-952 \mu \mathrm{m}$, which is $-25 \%$ of the total width.

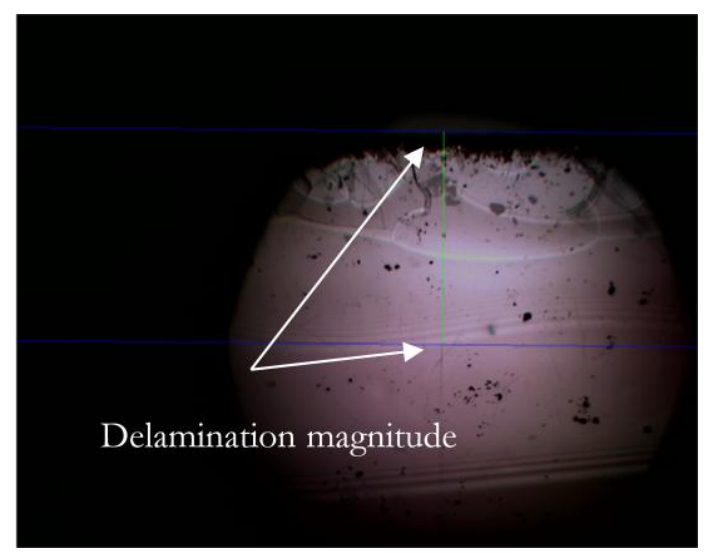

Fig.12. Delamination due to hand cut, $78 \mu \mathrm{m}$ thick sample.

There is little difference between this technique and the free side cut technique. Both used pressure to minimize the damage. The only difference is how to save the sample for the next cut, i.e. prevent the damage occurring to the rest of the sample in the free side cut technique.

\section{EXFOLIATE MICA BY HAND}

Exfoliating mica by hand requires a steady hand. Sudden movement often causes considerable damage to the sample or can even break it due to the brittleness of the material. Given this, the hand cut technique most likely varies from one person to another. A small blade edge can be slowly inserted between the layers of the mica, as shown in Fig. 13.

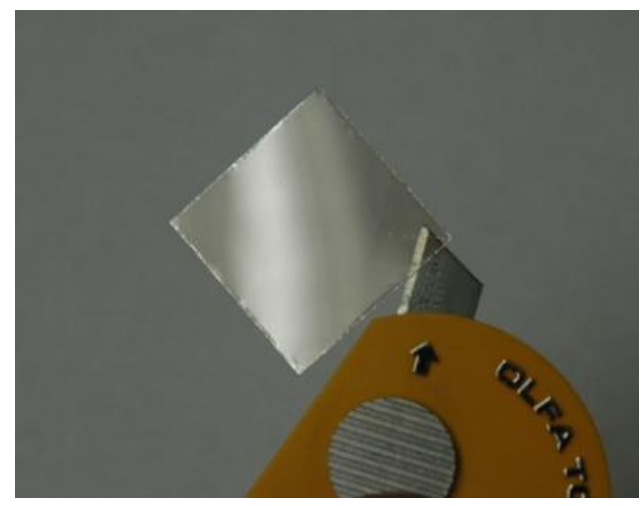

Fig.13. Blade inserted between laminate. 
Once the laminate begins to peel, the process is continued by hand, slowly until the sample is fully exfoliated. The desired thickness was difficult to obtain by a single peel; however, repeating the process increases the chance of getting the specified thickness.

Samples were inspected under the microscope to make sure they were free of scratches and major cracks. Usually, scratches come from the blade when it is inserted to peel the mica. Even a small scratch, especially for thicknesses $\leq 20 \mu \mathrm{m}$ could cause the sample to fail immediately after the preload stage. In general, for samples to reach the ultimate strength, they need to be free from any damage that might cause a stress concentration.

\section{EXPERIMENTAL PROCEDURE}

\section{BASIC PRINCIPLE}

The stresses at any point in a continuum can be represented by nine stress components as shown in Fig. 14.

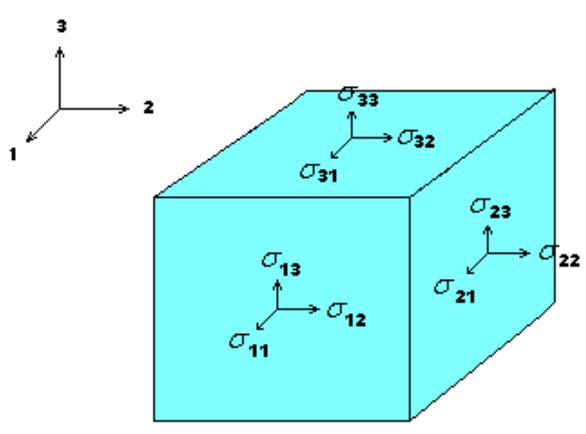

Fig. 14. Stress components in a continuum.

Out of these nine stress components, eight will vanish because the load is uniaxial. The following illustrates the stress matrix due to uniaxial loading.

$$
\sigma_{i j}=\left[\begin{array}{ccc}
\sigma_{11} & 0 & 0 \\
0 & 0 & 0 \\
0 & 0 & 0
\end{array}\right]
$$

The elastic modulus can be found experimentally from the slope in the elastic region. Fig. 15 shows two slopes, the upper curve representing brittle materials, such as mica and glass, and the lower curve generally describes the behavior of ductile materials, such as steel and aluminum.

The main difference between brittle and ductile materials is that brittle materials exhibit a small or even no plastic deformation, while ductile materials exhibit large plastic deformation before fracture.

In uniaxial loading, Hooke's law which relates stress to strain is given by:

$\sigma=\mathrm{E} \varepsilon$

where $E$ is the Young's modulus or modulus of elasticity, $\sigma$ is the stress and $\varepsilon$ is the strain.

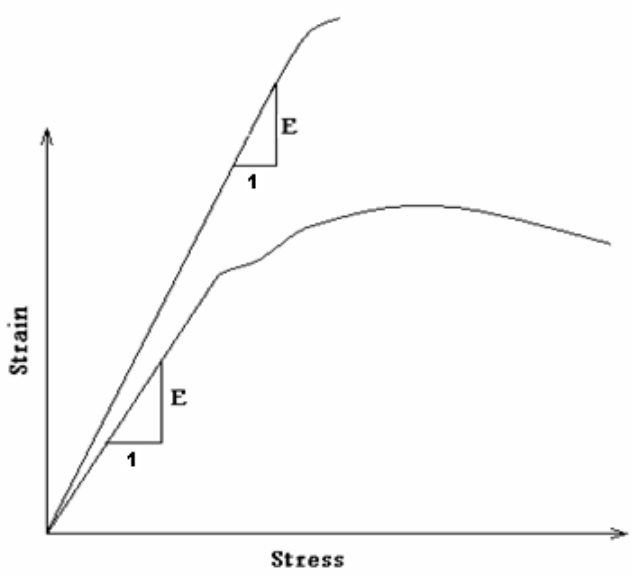

Fig.15. Stress-strain curve for brittle and ductile material behavior in general.

For an axial load, the normal stress is calculated from:

$\sigma=\frac{P}{A}$

where $P$ is the applied load and $A$ is the cross sectional area that is perpendicular to the applied load. The axial strain $\varepsilon$ is given by:

$\varepsilon=\frac{\Delta L}{L}$

and $L$ is the original length and $\Delta L$ is the elongation. Substituting Equations (5) and (6) in Equation (4) will lead to: 


$$
E=\frac{P L}{A(\Delta L)}
$$

The relation in Equation (7) was been used to determine Young's modulus experimentally.

\section{AsSUMPTIONS}

It was assumed that muscovite is homogeneous and linearly elastic and also isotropic in two dimensions.

\section{LOADING CONDITION}

The sample was mounted between two clamp grips as shown generally in Fig. 16; one of these clamps is fixed, while the other one is moving to make the sample suffer the load in tension. At the same time equal and opposite forces were automatically generated to maintain equilibrium.

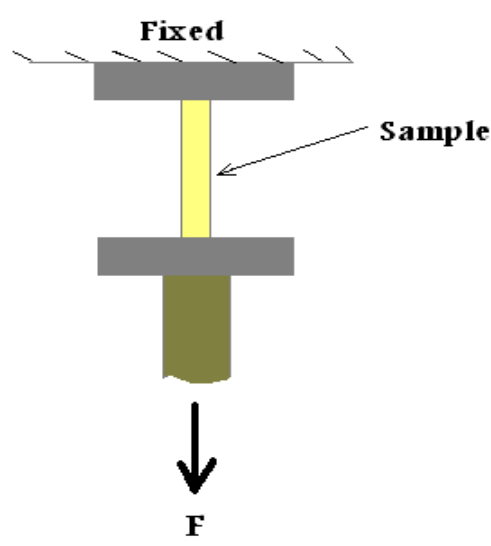

Fig.16. Sample under uni-axial tension.

The samples in these experiments were mounted as shown in Fig. 17(a), longitudinally parallel to the cleavage. Young's modulus parallel to the cleavage is almost three times that perpendicular to the cleavage [5]. The reason for this is that the covalent bonding within the mica layers is stronger than the ionic bonding which holds the layers together, i.e. anisotropic in three dimensional (3D).

According to McNeil [5], $E_{33}$ is measured to be $60.9 \pm 0.6 \mathrm{GPa}$ while, $E_{11}$ is $176.5 \pm 1.1$ $\mathrm{GPa}$. In general, the mechanical properties in the direction of the property $C_{33}$ are directly dependent on the ionic bonds which holds the layers together, see Fig. 17(b).

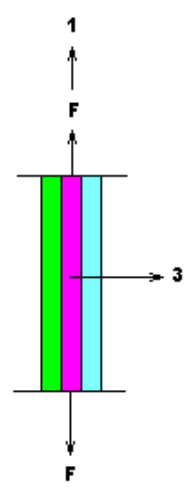

a)

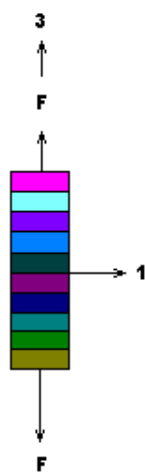

b)
Fig.17. (a) Laminate mounted along the 1 direction; (b) Laminate mounted along the 3 direction.

In conclusion, the properties in the 3 direction are affected directly by the strength of ionic bonding holding the layers together, while measuring the properties parallel to the cleavage is directly affected by the strength of the covalent bonding within the layer.

\section{RESULTS AND DISCUSSIONS}

The variety of thicknesses in the mica samples show different delamination occurrence and Young's modulus changed as a function of thickness. The average Young's modulus versus thickness is shown in Fig. 18 and the results are divided into three parts.

First, the Young's modulus found by $\mathrm{McNeil}$ [5] in the direction of the property $C_{11}$ is 176.5 $\pm 1.1 \mathrm{GPa}$. He used Brillouin scattering to measure the Young's modulus. The weighted average sum of the spacing $(d)$ in the McNeil experiment can be calculated using Bragg's law:

$$
2 d \sin \left(\frac{\phi}{2}\right)=\frac{\lambda_{o}}{n}
$$

where $\phi$ is the angle of reflection, $\lambda_{o}$ is the wave length in vacuum and $n$ is the index of 
reflection. McNeil (1992) used $\lambda_{o}=514.5 \mathrm{~nm}$ and the index of reflection for the mica is -1.55 [11]. As a result, the magnitude of the spacing calculated from Equation (8) is $\sim 0.16$, $\mu \mathrm{m}$ and this value is used for the thickness of mica used in McNeil work for the purpose of comparing his results with those of the current research.

The second result shown in Fig. 18 is what was measured by Katahara [9] using Equation (2). The Young's modulus was found to be 179.9 GPa where the thickness remained unknown. Because the thickness used in Katahara's experiment is unknown, a dotted line across the thickness was made.

The third result is obtained from the measurements performed using the procedure developed in this research. There are five different thicknesses, $20 \mu \mathrm{m}$ to $94 \mu \mathrm{m}$ with constant length and width, $15 \mathrm{~mm}$ and $4 \mathrm{~mm}$, respectively.

There is some agreement between the results found by McNeil [5], Katahara [9] and the results found in this research. Point $A$ in Fig. 18 indicates $E_{11}$ for McNeil which is $176.5 \pm 1.1 \mathrm{GPa}$ at $\sim 166 \mathrm{~nm}$ thickness, while point $B$ shows $E_{11}=178.3 \mathrm{GPa}$ which is the mean Young's modulus measured for $20 \mu \mathrm{m}$ thick samples found in this research.

In addition to all assumptions made and neglecting the cracks, we get sense of the effect of the delamination on the determination of the Young's modulus as shown from point $\mathrm{B}$ to point $\mathrm{C}$.

Fig. 18 shows a linear decrease in the Young's modulus from point $B$ to point $C$. This might result from the damage in general, which increased when the thickness increased.

Figure 18 also combines hand cut, fixture cut and hand cut/fully exfoliated samples (hand cut/fully exfoliated sample is a sample that was cut by hand and then split into two pieces). The average of Young's modulus of the hand cut seems to agree well with the value obtained with a fixture-cut specimen, as shown in point $\mathrm{F}$. From point $\mathrm{C}$ to $\mathrm{D}$, there is no significant change in Young's modulus; point $\mathrm{C}$ has $4 \%$ contacts between the layers while point $\mathrm{D}$ has $0 \%$ because the samples were fully exfoliated.

An improvement in the Young's modulus was noticed when the fixture cut was used (point E), as illustrated between point $\mathrm{D}$ and $\mathrm{E}$; because the fixture cut maintain pressure on

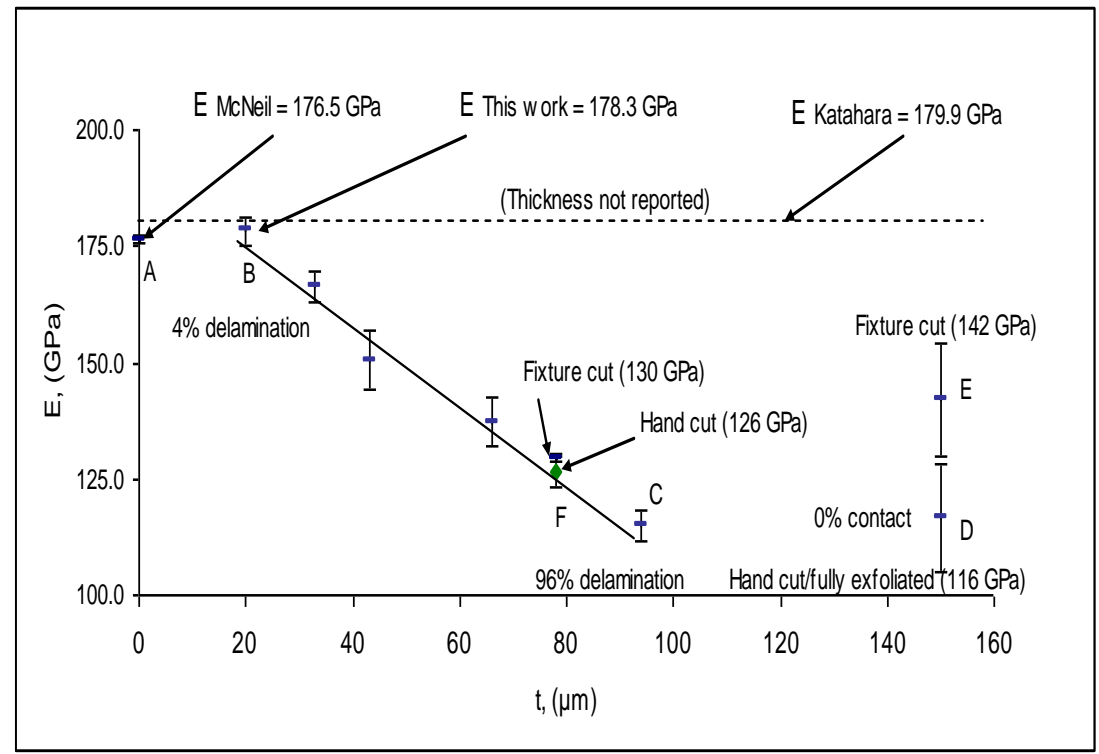

Fig.18. Comprehensive results for Young's modulus. 
the samples during the cutting process which minimizes damage.

\section{CONCLUSION}

Young's modulus was found to vary as a function of the mica laminate thickness, since the damage level changes in the samples. This damage consists of cracks and delamination at the sample's boundary. In general, this effect (damage) seems to decrease when the sample's thickness decreased. Because the damage consists of two dependent variables; i.e. cracks and delamination, it was unclear whether the reduction of the Young's modulus is caused by the delamination and/or cracks.

It appears that the failure mechanism might be even more complicated than that. Indeed, the assumptions made might not hold for thick samples; the composite structure of the mica may have initial imperfections and uncertainty of knowing the extent of the true contact between the layers.

The fixture cutting method of specimen preparation succeeded in minimizing delamination, but did not show any significant difference when compared with hand cutting techniques. The effect due to debonding was significant when the samples were fully exfoliated by hand.

There is an agreement between the Young's modulus found in this research and the modulus found by McNeil (1992) and Katahara (1996). The average value at $20 \mu \mathrm{m}$ thickness was $178.3 \mathrm{GPa}$ while the modulus found by McNeil is $176.5 \mathrm{GPa}$.

For thicker samples $(-33 \mu \mathrm{m} \leq t \leq-94 \mu \mathrm{m})$, the Young's modulus decreased linearly when the samples thickness increased, reaching a mean value of $115 \mathrm{GPa}$. This finding can be rationalized because of the damage occurring within and between the laminate varies with the thickness. Furthermore, it was assumed that the laminate structure of the mica is homogeneous; this assumption depends on the characteristic volume, i.e. mica is heterogeneous at the nano-scale and homogeneous at the micro scale. In addition, the delaminations between the layers could violate the homogeneity assumption even on a micro-scale level.

Cutting muscovite samples with a fixture designed to provide and maintain equal pressure shows improvement in Young's modulus along the direction of the property $C_{11}$, compared with the hand-cut fully exfoliated procedure. In addition, the Young's modulus was not altered using the pressure fixture cut when compared to hand-cut samples. From these results it can be concluded that, the weak bonding which hold the layers together, could carry and/or transmit loads and is a key element to the overall stiffness of mica.

\section{ACKNOWLEDGMENT}

I would like to thank the government of Saudi Arabia including the Royal Commission for Jubail \& Yanbu, Yanbu Industrial College and South Dakota School of Mines and Technology for funding this research.

\section{REFERENCES}

[1] Schematic of mica [on-line graphic]. Web minerals data. February 24, 2007: http://webmineral.com/data/Muscovite.shtml

[2] Bailey, S.W., Reviews in Mineralogy, Mineralogical Society of America, 1984.

[3] Miyake, Shojiro, "1 $\mathrm{nm}$ deep mechanical processing of muscovite mica by atomic force microscopy", Nippon Institute of Technology, 67, 1995, pp. 2925-2927.

[4] Xanthos, M., Functional fillers for plastics, WILEY-VCH Verlag GmbH \& Co KGaA, 2005.

[5] McNeil, L. E., Elastic Moduli of muscovite mica, IOP Pub. 5, 1992, pp. 1681-1690. 
[6] ASTM D882, "Standard test method for tensile properties of thin plastic sheeting", ASTM standard, 8.01, 1997, pp.165-173.

[7] Prasad, M., "Measurement of Young's modulus of clay minerals using atomic force acoustic microscopy", American Geophysical Union. 29, 13.1-13.4, 2002.

[8] ASTM E1875, "Standard Test Method for Dynamic Young's Modulus, Shear Modulus, and Poisson's Ratio by Sonic Resonance”, ASTM standard, 3.01, 2000.

[9] Katahara, K. W., Clay mineral elastic properties, ARCO publication. 15, 1996, pp. 1691-1694.

[10] Information and tips about cutting mica in your laboratory,

http://www.2spi.com/catalog/submat/micainformation-cutting.html, October 15, 2006

[11] Antique Stoves.com, http://www.antiquestoves.com/mica/properties/in dex.htm, Feb, 42007

[12] Surface brillouin scattering, http://www.soest.hawaii.edu/ zinin/Zi-

Brillouin.html, Feb, 102007 


\section{تحديد الخواص المرنة لمركب المايكا}

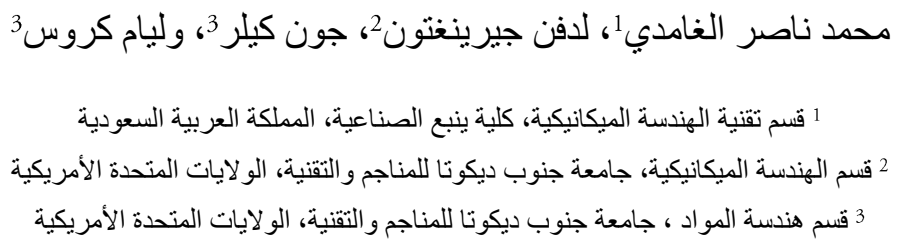

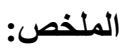

التركيب الصفائحي للمايكا معقدة جدا، وذلك بسبب سلوكها المنباين في اتجاه الخاصية C 33 ، ولذلك توجد صعوبة في قطع عينات الميكا، خاصة عندما يكون المطلوب عينات سميكة نسبيا. من السهل نسبيا قطع العينات الرقيقة بما لا يخلف الكثير من الضرر فيما الكثير من الضرر للعينات السميكة. يتألف الضرر من الثقوق العمودية والمتو ازية علي جسم المادة مما يغير خواص المركب. الهدف الرئيسي من هذا البحث هو تحديد معامل المرونة باستخدام سماكات مختلفة.

وتم التوصل إلى أنه ينخفض معامل المرونة تدريجيا مع سماكة المركب للوصول الى 15 ج.ب لسماكة 94 ميكرون من المركب. هذا يعني ان هناك انخفاض في معامل المرونة بواقع 35 \% عند زيادة السماكة بواقع 79\%. من هذة النتائج اتضح أن التلاصق الأستاتيكي الضعيف بين رقائق المايكا هو من يساعد على انتقال وتوزيع القوي بين المركب مما يعطي المركب خاصية استثنائية بين المركبات المماثلة ويفتح المجال لإعادة قر اءة حيثيات الاستفادة من هذا المركب. 